\title{
Acute thrombosis during distal left main stenting using tap technique in patient presenting with non st-elevation acute coronary syndrome
}

\begin{abstract}
This case reports the sudden development of large burden of thrombi in the left anterior descending coronary artery immediately following distal left main Stenting using TAP technique in a middle aged man who presented with non ST-segment elevation acute coronary syndrome despite having been administered 7,500units of unfractionated heparin and being given $325 \mathrm{mg}$ of aspirin and $60 \mathrm{mg}$ of prasugrel prior to the procedure. The thrombi were managed effectively by giving an intra-coronary high bolus dose of tirofiban $(25 \mathrm{mcg} /$ $\mathrm{Kg}$ ) without the need for catheter thrombus extraction. Tirofiban intra-venous infusion was maintained for 18 hours and the patient was discharged in stable condition on the third day.
\end{abstract}

Volume I Issue 5 - 2014

\author{
Deepak Natarajan \\ Department of Interventional Cardiology, Park Hospitals, India
}

Correspondence: Deepak Natarajan, Department of Interventional Cardiology, Park Hospitals, Delhi, NCR, India, Tel 919868101010, Email deepaknatarajan19@gmail.com

Received: October 3I, 2014 | Published: November 6, 2014

Keywords: unprotected distal left main disease, thrombus, distal left main tap stenting, prasugrel, tirofiban

Abbreviations: UPLMS, unprotected left main stem; MACCE, major cardiovascular and cerebral events; ACS, acute coronary syndrome; LCX, left circumflex; LAD, left anterior descending; PCI, percutaneous intervention; ZES, zotarolimus eluting stent; PRECOMBAT, Patients With Left Main Coronary Artery Disease; NSTEACS, Non-ST Elevation Acute Coronary Syndrome; IVUS, intra-vascular ultrasound

\section{Introduction}

Coronary artery bypass graft surgery continues to hold its preeminent position as treatment of choice for significant unprotected left main stem (UPLMS) artery disease. Recent randomized trials have however suggested that PCI may be considered reasonable alternative to CABG if the anatomy of LM disease is suitable and in acute coronary syndrome settings. ${ }^{1-6}$ The SYNTAX trial randomly assigned 705 patients with distal LM disease to CABG or PCI and at 5years follow up rates of death $(\mathrm{CABG}=14.6 \%$ vs. $\mathrm{PCI}=12.8 \%$; $\mathrm{P}=0.53)$ and myocardial infarction $(\mathrm{CABG}=4.8 \%$ vs. $\mathrm{PCI}=8.2 \%$ $\mathrm{P}=0.10)$ were not significantly different. There were more strokes with CABG than PCI ( $15 \%$ vs. $4.3 \%$; $\mathrm{P}=0.03)$ but repeat revascularization were lesser in the surgery patients $(15.5 \%$ vs. $26.7 \% ; \mathrm{P}<0.001)$ and no significant difference in overall major cardiovascular and cerebral events (MACCE). Importantly MACCE rates were comparable in the lower (0-22) and intermediate (22-32) SYNTAX score tertiles. There is paucity of data on PCI intervention in acute coronary syndrome (ACS) settings when surgery may be contraindicated. ${ }^{7-10}$ this case report describes the treatment of large thrombi suddenly appearing in the LAD artery soon after distal left main Stenting using the T and protrusion (TAP) Stenting technique in a patient who presented with an impending myocardial infarction

\section{Case presentation}

A 55year old hypertensive man who had been smoking for the last 4decades was admitted in the ER with severe retrosternal chest pain, radiating to both arms, for the previous 2 hours. His pain was not relieved with sublingual nitroglycerin. On examination his heart rate was 78 /minute, respiration 22 /minute, O2saturation at room air was $92 \%$, there were minimal basal crackles in both lungs, and a loud fourth heart sound. His 12 lead ECG showed sinus rhythm, ST segment coving in leads L1, AVL, V4-V6 accompanied with T wave inversion in these leads (Figure 1). Troponin $\mathrm{T}$ was positive; CK was 1,700units and CK-MB 215units. The 2D colour Doppler echocardiogram revealed global hypokinesia of the left ventricle, left ventricle ejection fraction of $40 \%$, with mild mitral regurgitation.

The patient was wheeled into the catch lab after pre-loading with $60 \mathrm{mg}$ Prasugrel and $300 \mathrm{mg}$ of Aspirin. He received 7,500units of unfractionated heparin and underwent coronary angiography from the right femoral route, which revealed $70 \%$ distal left main (LM) stenosis, and $70-80 \%$ ostial blocks of the left anterior descending (LAD) and left circumflex (LCX) arteries (Figures 2 \& 3), (Video 1). The right coronary artery had a $50 \%$ stenosis at mid level (Figure 4). The patient was continuing to have chest pain despite prior administration of intra-venous morphine in the ER. He however was in a position to give informed consent for primary percutaneous intervention (PCI) subsequent to explaining that PCI would be a viable alternative keeping in view the urgency of intervention in his condition.

A 7 Fr EBU guiding catheter was employed to engage the LM artery and two BMW 0.014 wires were placed in the distal LAD and LCX arteries. The LM-LAD lesion was pre-dilated with a $2.5 X 15 \mathrm{~mm}$ balloon and a $3 \mathrm{X} 18 \mathrm{~mm}$ zotarolimus eluting stent (ZES) was deployed covering the LM and LAD stenosis (Figure 5). Proximal optimization was done by placing a $3.5 \times 9 \mathrm{~mm}$ non-compliant (NC) balloon at the bifurcation of the LM artery and inflating it to 10atm (Figure 6). One more BMW wire was negotiated through the distal struts of the LM-LAD stent into the LCX artery (Figure 7), and the jailed wire withdrawn.

The struts at the LCX artery ostium were opened by a $2 \mathrm{X} 12 \mathrm{~mm}$ balloon; a $3 \mathrm{X} 15$ non-compliant balloon was parked in the LM-LAD stent across the LCX ostium, and then a $2.75 \mathrm{X} 22 \mathrm{~mm}$ ZES was positioned such that it's proximal marker was at the lower shoulder of the carina and in between the 2 markers of the balloon parked within the LM-LAS stent (Figure 8), (Video 2). The LCX stent was deployed at 14atm, the balloon was withdrawn into the LM-LAD stent and kissing done with the parked LM-LAD balloon at 10atm (Figure 9). 
A check shot done at this stage of the procedure demonstrated fully expanded LM-LAD and LCX stents with brisk TIMI 3 flow into both arteries, but large fragments of thrombi appeared in the LAD artery (Figure 10), (Video 3) The patient complained of chest discomfort and this was accompanied with slight lowering of heart rate and drop in blood pressure. An intra-coronary (IC) bolus injection of tirofiban $(20 \mathrm{mcg} / \mathrm{Kg})$ was immediately administered and this rapidly completely lysed the thrombi in the LAD artery (Figures 11 \& 12), (Video 4). The patient was shifted to the CCU on intra-venous tirofiban infusion for the next 18 hours. His further stay in hospital was unremarkable, and he was discharged on the third day in stable condition on aspirin, prasugrel, atorvastatin, ramipril and metoprolol.

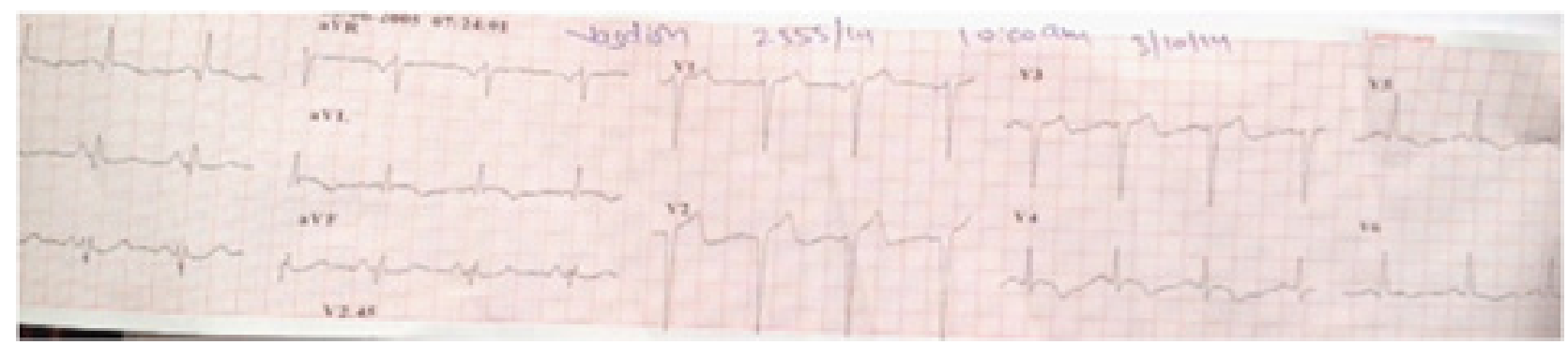

Figure ITwelve lead ECG exhibiting ischemic changes in leads LI, AVL,V4-V6.

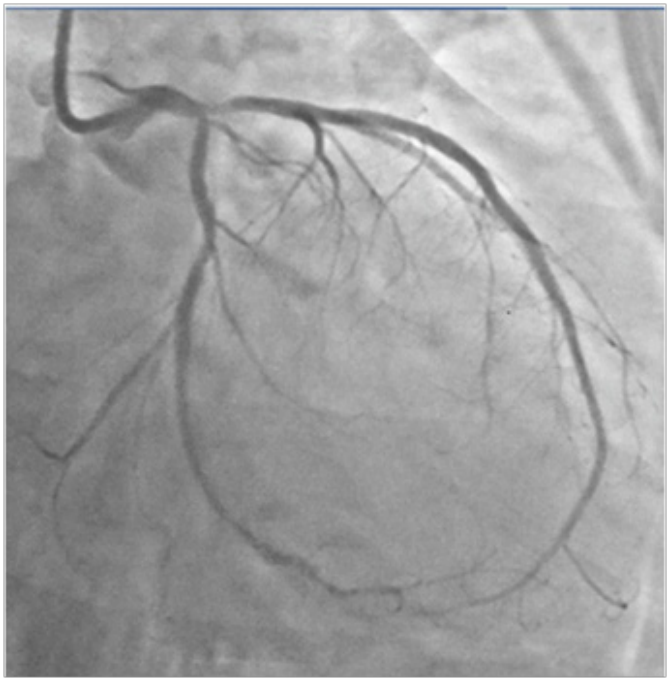

Figure 2 Coronary angiogram in right anterior oblique caudal view showing tight distal left main and ostial left anterior descending coronary arteries stenosis.

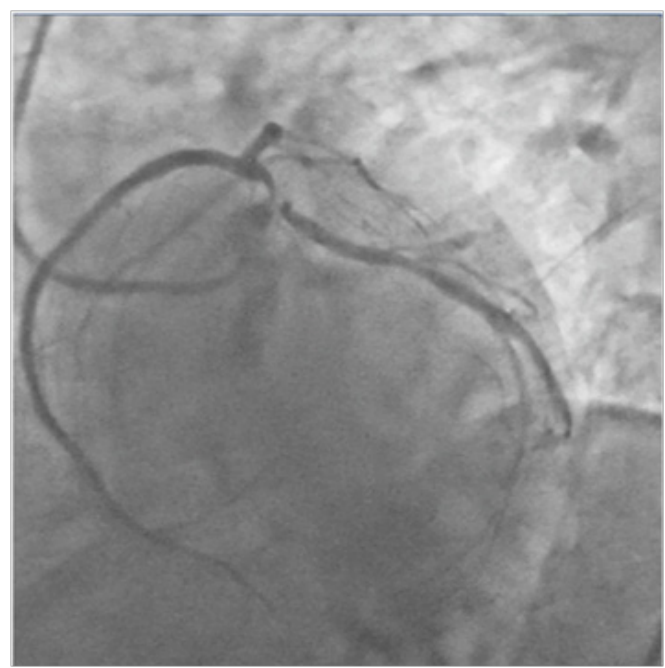

Figure 3 Spider view showing tight distal left main, ostial left anterior descending and ostial left circumflex arteries stenosis.

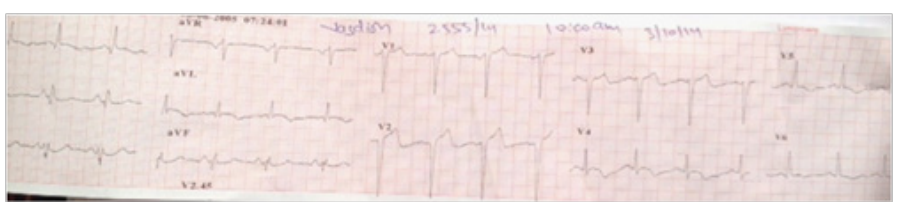

Video I

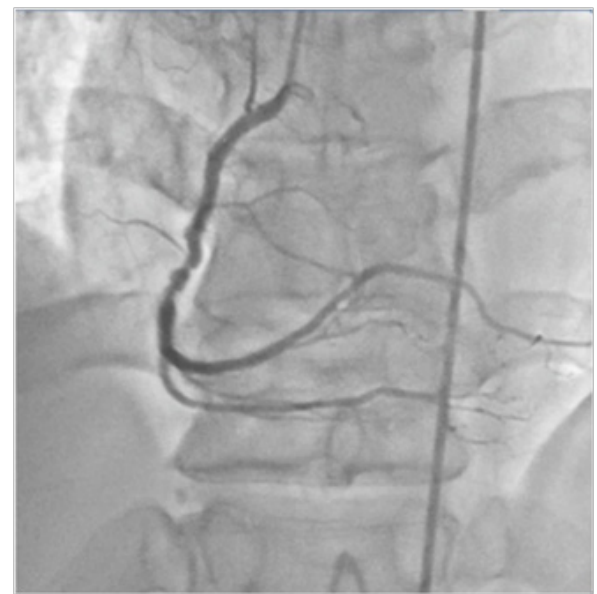

Figure 4 Right coronary artery with lesion in med segment.

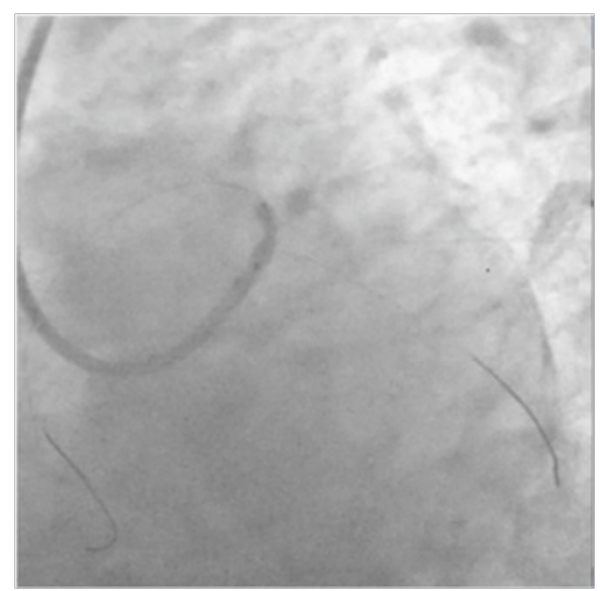

Figure 5 Zotarolimus eluting stent (ZES) being deployed from LM to LAD artery. 


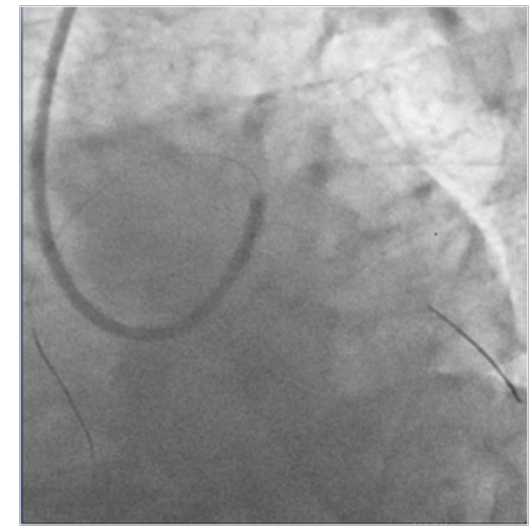

Figure 6 Proximal optimization of LM-LAD stent with $3.5 \times 8 \mathrm{~mm}$ balloon.

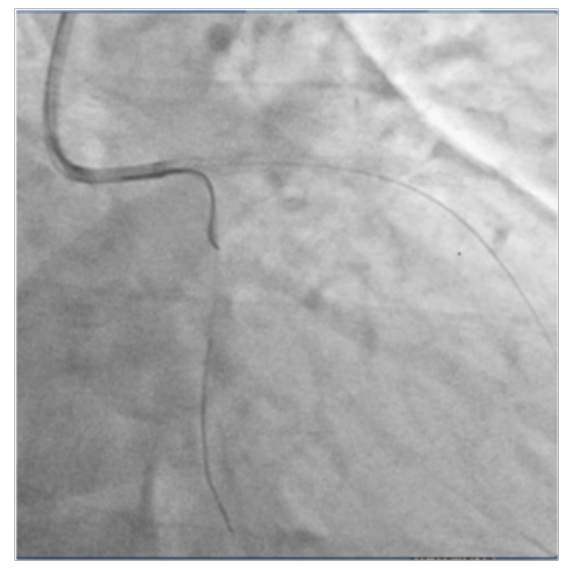

Figure 7 Third BMW wire being easily negotiated into LCX artery through struts of LM-Lad stent after proximal optimization.
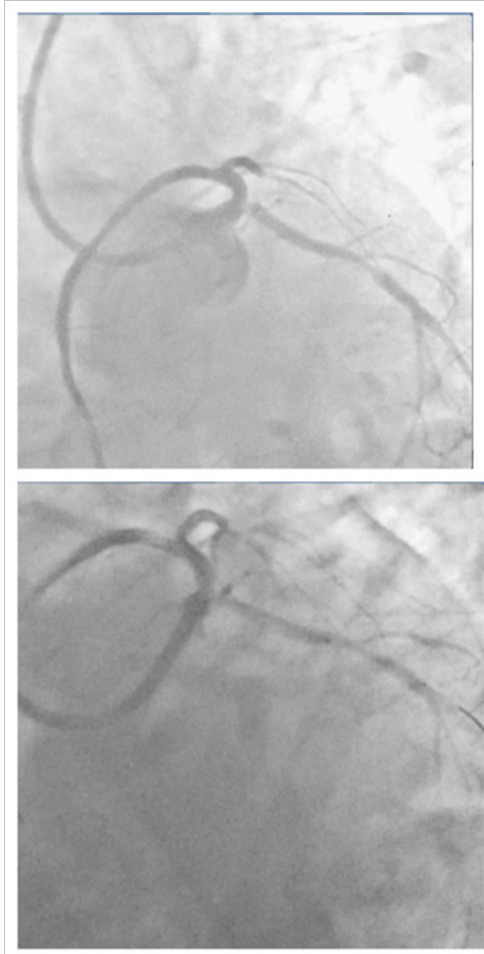

Figure 8 Second ZES being positioned to cover osmium of LCX with proxima marker on lower shoulder of carina and at middle of the two markers of the balloon parked in LM- LAD stent.

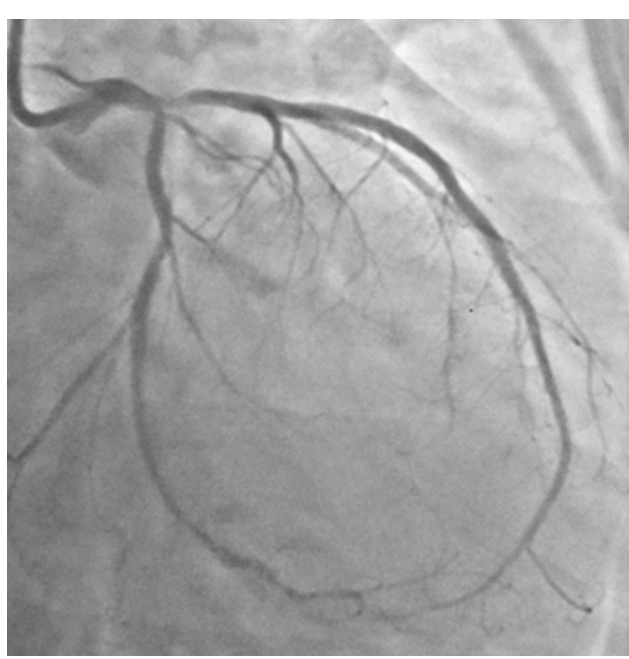

Video 2

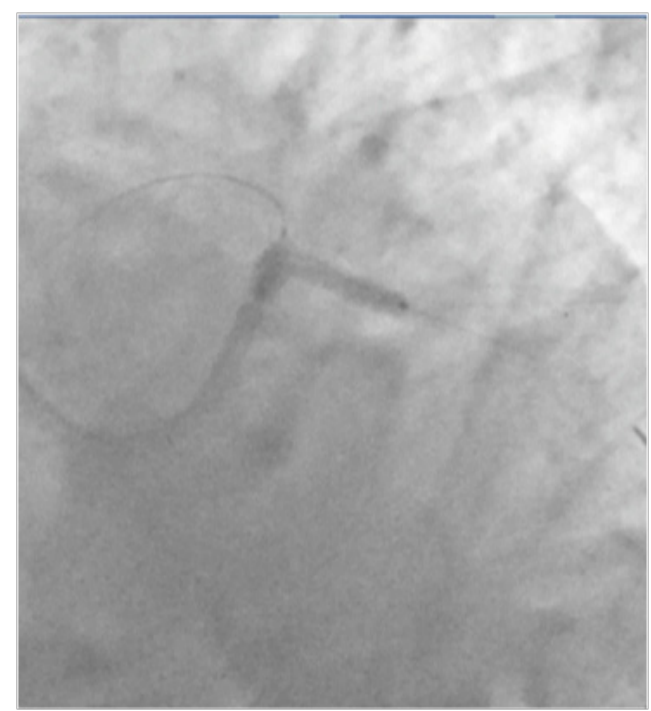

Figure 9 Kissing ballon after withdrawing LCX stent balloon and LM-LAD balloon.

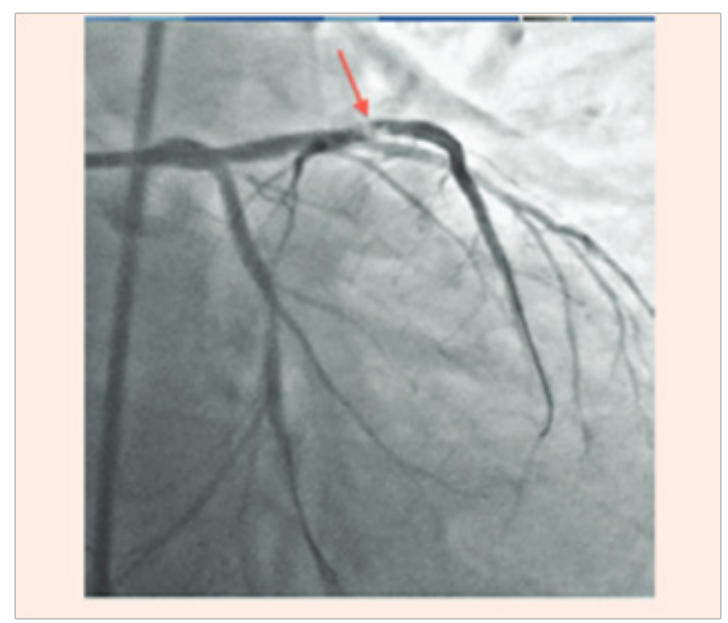

Figure 10 Check shot done after kissing balloon shows large burden of thrombi in LAD artery and no re-flow in distal artery, necessitating intracoronary high doses tirofiban administration $(25 \mathrm{mcg} / \mathrm{Kg}$ ). 


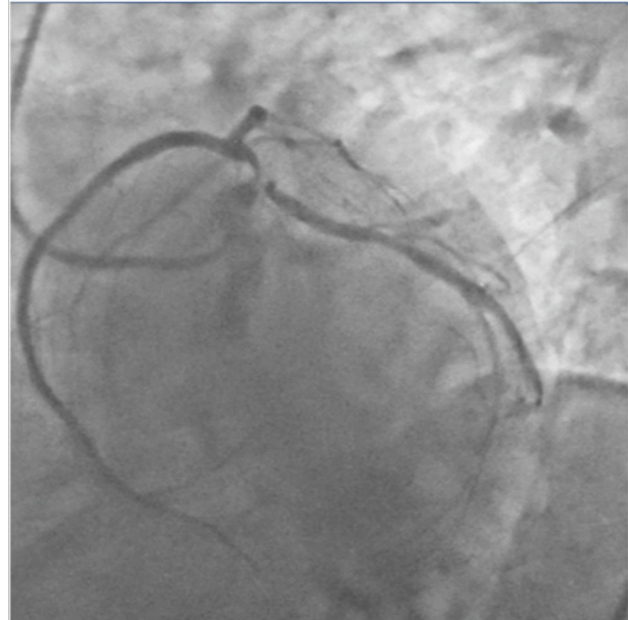

Video 3

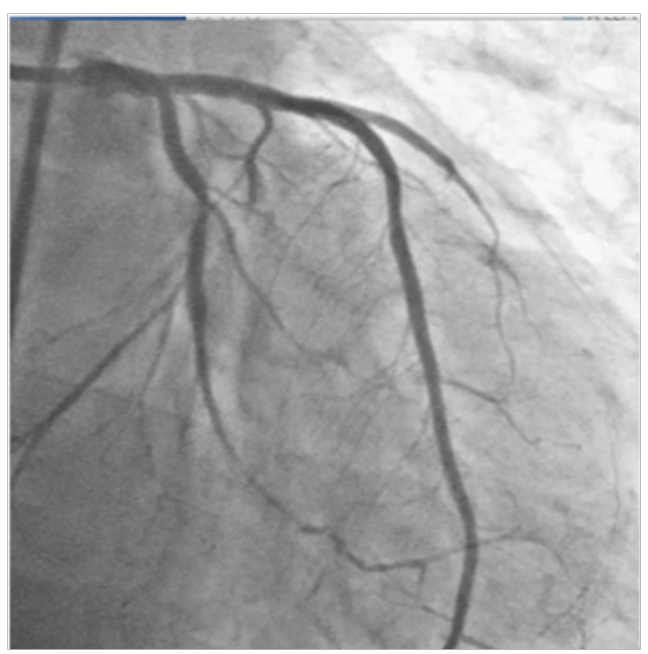

Figure I I Fully expanded ( angiographically) stents in LM-LAD and LCX arteries, with TIMI 3 flow and no dissection.

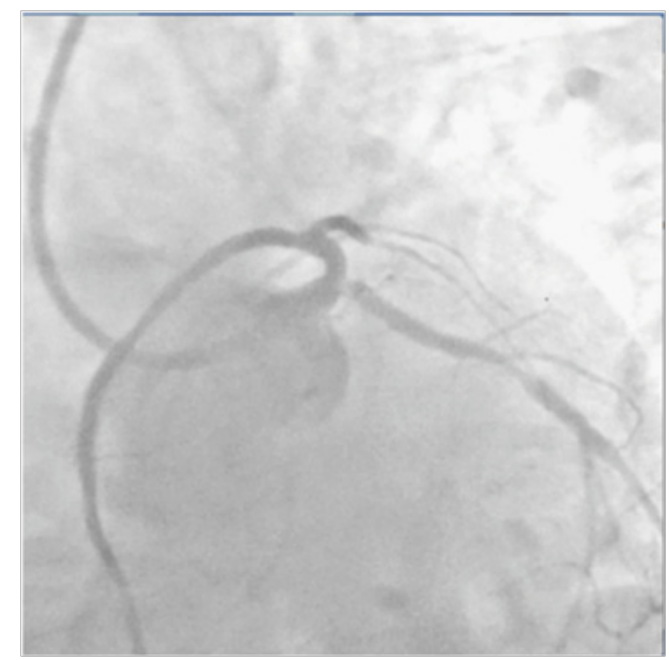

Figure I 2 Fully expanded LM-LAD and LCX stents with brisk TIMI 3 ante grade flow in both arteries.

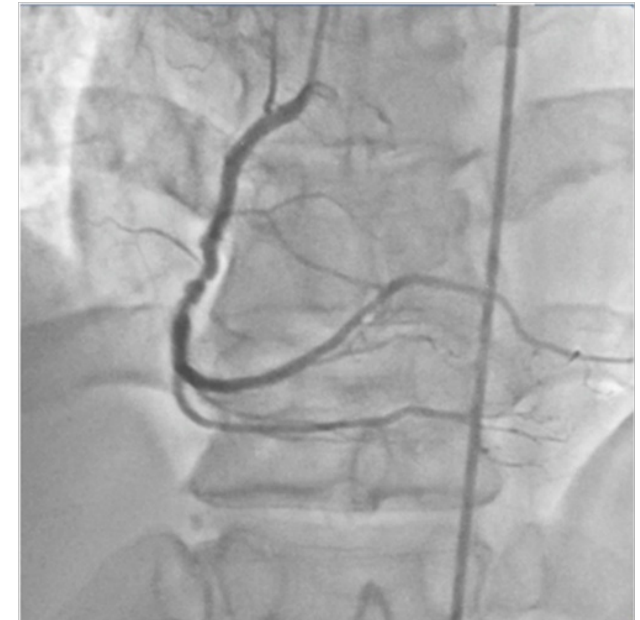

Video 4

\section{Discussion}

The Premier of Randomized Comparison of Bypass Surgery vs. Angioplasty Using Sirolimus-Eluting Stent in Patients with Left Main Coronary Artery Disease (PRECOMBAT) trial randomized 600 patients with LM disease to PCI or coronary surgery. The one year composite rate of death, myocardial infarction or stroke was similar for both groups (3.3\% for PCI and 4\% for CABG; $\mathrm{P}=0.66)$. Similar clinical outcomes were maintained at 2years (mortality of $2.4 \%$ with PCI vs. $3.4 \%$ with $\mathrm{CABG} ; \mathrm{P}=45$ ). ${ }^{11}$ This case, however, reports $\mathrm{T}$ (and protrusion) Stenting in a patient presenting with impending anterior ST-elevation with distal LM stenosis involving Ostia of the LAD and LCX. A recent British registry has reported mortality as high as $28.3 \%$ at 30 days. Risk of 30 day mortality was significantly greater in patients with ST-elevation myocardial infarction and non-ST elevation acute coronary syndrome (NSTEACS) than in patients with chronic stable angina. Patients with STEMI presenting with shock (more than 40\%) had greater mortality at 30 days than patients without shock (52.0\% vs. $11.7 \%$ ). Patients with UPLMS presenting with STEMI or NSTEACS are at greater risk of death than stable angina elective cases. ${ }^{12}$

The British registry reports that femoral access was used in twothirds of patients, bare metal stents were used in 36\% of STEMI and in $25 \%$ of NSTEACS patients, Intra-vascular ultrasound (IVUS) was used more frequently in elective cases (CSA:36\%, STEMI:14.6\% and NSTEACS:30\%). An intra-aortic balloon pump was inserted in 39\% of STEMI and in $17 \%$ of NSTEACS patients. Glycoprotein IIb/IIIa inhibitor abciximab was used in 60\% STEMI, 29\% NSTEACS and in $24 \%$ CSA patients. A meta-analysis of 24 studies (including 14,203 patients) looked at clinical outcomes when PCI with drug eluting stents was compared with CABG in unprotected left main disease and concluded that PCI with DES was a safe and durable alternative to CABG for unprotected LM disease at 1 year. ${ }^{11}$ The current American College of Cardiology/ American Heart Association guidelines have upgraded PCI of unprotected LM disease from Class III indication in 2006 to a Class IIb indication in 2009, and to class IIa indication in 2011, when surgical risk is high and anatomy is favorable. ${ }^{6}$

Facilitated PCI for STEMI or the administration of pharmacological substances before primary PCI, have been found not to offer clinical benefits over primary PCI, and in fact resulted in increased bleeding complications. ${ }^{13,14}$ More than 2,400 patients with STEMI were randomized to 3 groups; early treatment with abciximab plus half dose 
reteplase (combination facilitated PCI, abciximab alone (abciximabfacilitated PCI, and abciximab administered immediately before the procedure (primary PCI) by the FINESSE investigators. There was no improvement in clinical outcomes either with combination facilitated PCI or abciximab facilitated PCI compared to primary PCI. ${ }^{15}$ A couple of years later a randomized study using high bolus dose (HBD) of tirofiban used early in the ambulance concluded that clinical outcomes were improved with HBD tirofiban in STEMI patients with a trend toward reduced mortality. ${ }^{16}$

The introduction of new ant-platelet agents such as prasugrel and ticagrelor having quicker onset and more powerful anti-platelet effects than clopidrogel may challenge the use of GPI's in STEMI. Both new agents have shown lower clinical events including stent thrombosis than clopidrogel. In the TRITON-TIMI 38 (Trial to Assess Improvement in Therapeutic Outcomes by Optimizing Platelet Inhibition with Prasugrel-Thrombolysis in Myocardial Infarction 38) operators used GPI's in $60 \%$ of patients, while in the PLATO trial with ticagrelor $40 \%$ of patients were administered a GPI. There was however little clinical improvement with the addition of a GPI to prasugrel in the TRITON study, and nor was there excess bleeding ${ }^{17-19}$

There is however little or no randomized data on safety and efficacy of GP IIb/IIIa inhibitors (GPI) in patients with LM disease in the setting of acute coronary syndrome, particularly patients presenting with NSTEACS. The patient presented in this case report presented with on-going severe chest but without classic ST-segment elevation in his ECG. His cardiac enzymes were substantially raised and should ideally be placed somewhere in between STEMI and NSTEACS. Multiple thrombi developed in his LAD artery soon after TAP of distal LM stenosis involving Ostia of LAD and LCX arteries, despite prior administration of 7,500units of unfractionated heparin, oral intake of $325 \mathrm{mg}$ aspirin and $60 \mathrm{mg}$ prasugrel. This was successfully managed with intra-coronary high bolus injection of tirofiban, without in this case the need for catheter thrombus extraction. There is need for randomized trials to assess the timing, safety and efficacy of GPI's in patients with LM disease presenting with acute coronary syndrome, who have received the prasugrel or ticagrelor. This case report suggests the added value in the catheterization laboratory of GP IIb/ IIIa inhibitors in patients who have been administered the newer more potent rapid onset anti -platelet agents.

\section{Acknowledgments}

None.

\section{Conflicts of interest}

Authors declare that there are no conflicts of interest.

\section{References}

1. Boudriot E, Thiele $\mathrm{H}$, Walther $\mathrm{T}$, et al. Randomized comparison of percutaneous coronary intervention with sirolimus stents versus coronary artery bypass grafting in unprotected left main stenosis. J Am Coll Cardiol. 2011;57(5):538-545.

2. Morice MC, Serruys PW, Kappetein AP, et al. Outcomes in patients with de novo left main treated with either percutaneous coronary intervention using paclitaxel-eluting stents or coronary artery bypass graft treatment in the synergy between percutaneous coronary intervention with TAXUS and Cardiac Surgery (SYNTAX) trial. Circulation. 2010;121(24):26452653

3. Morice MC, Serruys PW, Kappetein AP, et al. Five Year Outcomes in Patients with Left Main Disease Treated with Either Percutaneous Coronary Intervention or Coronary Artery Bypass Grafting in the SYNTAX Trial. Circulation. 2014;129(23):2388-2394.
4. Capodanno D, Stone GW, Morice MC, et al. Percutaenous coronary intervention vs. coronary bypass graft surgery in left main coronary artery disease:a meta analysis of randomized clinical data. J Am Coll Cardiol. 2011;58(14):1426-1432.

5. Windecker S, Kolh P, Alfonso F, et al. 2014 ESC/EACTS Guidelines on myocardial revascularization. The Task Force on Myocardial Revascularization of the European Society of Cardiology (ESC) and the European Association for Cardio Thoracic Surgery (EACTS). Eur Heart J. 2014;35(37):2541-2619.

6. Levine GN, Bates ER, Blankenship JC, et al. 2011 ACCF/AHA/SCAI guidelines for percutaneous coronary intervention: a report of the American College of Cardiology Foundation/American Heart Association Task Force on Practice Guidelines and the Society for Cardiovadscular Angiography and Interventions. Circulation. 2011;124(23):e574-e651.

7. Meliga E, Garcia Garcia HM, Valmigli M, et al. Impact of drug stent selection on long term clinical outcomes in patients treated for unprotected left main coronary disease. The sirolimus vs paclitaxel drug-eluting stent for left main registry (SP DELFT). Int J Cardiol. 2009;137(1):16-21.

8. Parma A, Fiorilli R, DE Felice F, et al. Early and mid term clinical outcome of emergency PCI in patients with STEMI due to unprotected left main coronary artery disease. J Interv Cardiol. 2012;25(3):215-222.

9. Celik T, Iyisoy A. The emerging role of percutaneous coronary intervention in the management of unprotected left main coronary artery disease: ongoing debate. Int J Cardiol. 2012;144(1):90-91.

10. Athappan G, Patvardhan E, Tuzcu M, et al. Left Main Coronary Artery Stenosis: A Meta-Analysis of Drug-Eluting Stents versus Coronary Artery Bypass Grafting. JACC Cardiovasc Interv. 2013;6(12):1219-1230.

11. Park SJ, Kim YH, Park DW, et al. Randomized trial of stents vs. bypass surgery for left main coronary disease. N Engl J Med. 2011;364(18):17181727.

12. Almudarra SS, Gale CP, Baxter PD, et al. Comparative Outcomes After Unprotected Left Main Stem Percutaneous Coronary Intervention. A National Linked Cohort Study of 5,065 Acute and Elective Cases From the BCIS Registry (British Cardiovascular Intervention Socoety). JACC Cardiovasc Interv. 2014;7(7):717-730.

13. Keeley EC, Boura JA, Grines CL. Comparison of primary and facilitated percutaneous coronary interventions for ST elevation myocardial infarction: quantitative review of randomized trials. Lancet 2006;367(9510):579-588

14. Stone GW, Gersh BJ. Facilitated angioplasty: paradise lost. Lancet 2006;367(9510):543-546.

15. Ellis SG, Tendera M, de Belder MA, et al. Facilitated PCI in patients with ST-elevation myocardial infarction. $N$ Engl J Med. 2008;358(21):22052217

16. Ten Berg JM, Van't Hof AWJ, Dill T, et al. On behalf of the On-TIME 2 Study Group. Effect of early, pre-hopsital initiation of high bolus tirofiban in patients with ST-segemnt elevation myocardial infarction on short-and long term clinical outcome. J Am Coll Cardiol. 2010;55(22):2446-2455.

17. Montalescot G, Wiviott SD, Braunwald E, et al. Prasugrel compared with clopidogrel in patients undergoing percutaneous coronary intervention for DT elevation Myocardial infarction (TRITON TIMI 38): double blind randomized controlled trial. Lancet. 2009;373(9665):723-731.

18. Wallentin L, Becker RC, Budaj A, et al. PLATO Investigators. Ticagrelor versus clopidogrel in patients with acute coronary syndromes. $N$ Engl $J$ Med. 2009;361(11):1045-1057.

19. O’ Donoghue M, Antman EM, Braunwald E, et al. The efficacy and safety of prasugrel with and without a glycoprotein IIb/IIIa inhibitor in patients with acute coronary syndromes undergoing percutaneous intervention. $J$ Am Coll Cardiol. 2009;54(8):678-685. 